American Journal of Applied Sciences 7 (6): 773-779, 2010

ISSN 1546-9239

(C) 2010Science Publications

\title{
Minimum and Complete Fluidization Velocity for Sand-Palm Shell Mixtures, Part II: Characteristic Velocity Profiles, Critical Loading and Binary Correlations
}

\author{
${ }^{1}$ V.S. Chok, ${ }^{2}$ A. Gorin and ${ }^{2}$ H.B. Chua \\ ${ }^{1}$ Department of Chemical Engineering, University Technology PETRONAS, \\ 31750 Tronoh, Perak, Malaysia \\ ${ }^{2}$ School of Engineering and Science, Department of Chemical Engineering, \\ Curtin University of Technology Sarawak Campus, \\ CDT 250, 98009 Miri, Sarawak, Malaysia
}

\begin{abstract}
Problem statement: In Part I of this research, the main features of the fluidization behavior and characteristic velocities had been reported. Approach: In the present research, the mixtures characteristic velocity profiles for various sand sizes, palm shell sizes and weight percents were presented. It was recognized that there are instances where the characteristic values remain nearly unchanged from its pure sand values. This regime of constant values can be observed in both compartments and can be established depending on the bed properties. The term "Critical loading" is then selected to define the maximum palm shell content (size and weight percent) that can be present in the mixtures where the characteristic velocities remain absolutely of pure sand values. Results: The critical loading increases with the increase of sand size but decreases with the increase of palm shell size. Moreover, it can be observed that the critical loading generally decreases with the increase in particle size ratio, although exception is sighted in the combustor for the mixture with the largest sand size. Overall, the largest sand size has the highest critical loading. Meanwhile, the selected correlations are able to describe the qualitative variation in the characteristic velocities. However, quantitatively, these correlations are unsatisfactory as they are either over-estimate or under-estimate. Conclusion/Recommendations: It is desirable to establish the regime of critical loading since the mixture characteristic velocities can be pre-determined using bed material properties made up from pure sand (inert) values. Within this regime, a single operational velocity can be set for respective compartment that is independent from variation of palm shell size and weight percent in the mixtures (especially during combustion or gasification). Ultimately, the state of fluidization (e.g., bubbling or vigorously fluidized) and mixing/segregation condition that depend on relative magnitude of operational and characteristic velocities can be identified and maintained.
\end{abstract}

Key words: Biomass mixing, fluidization velocity, binary correlations

\section{INTRODUCTION}

Palm shell cannot be fluidized solely. It is considered as Geldart D particle, a classification for spouting material. However, the addition of a second fluidizable material (sand) in palm shell can facilitate proper fluidization. In Part I of this research (Chok et al., 2009a), the main features of the fluidization behaviour and characteristic velocities using sand-palm shell mixtures were examined with respect to different bed properties. Their distinct patterns and further analysis on the various characteristic velocity relationships provide insights on the fluidization mechanism and the mixing/segregation tendency. Some interesting works are given in (Chok et al., 2009b; 2007; Fauziah et al., 2008) on hydrodynamic studies of sand-palm shell mixtures. Interested readers are encouraged to refer to them.

The present study reports the characteristic velocity profiles for various sand sizes, palm shell sizes and weight percent in the mixtures and in different compartments. As described later, it is recognized that there are some instances where the mixtures $\mathrm{U}_{\mathrm{mf}}$ and $\mathrm{U}_{\mathrm{cf}}$ values remain nearly unchanged from its pure sand values.

Corresponding Author: V.S. Chok, Department of Chemical Engineering, University Technology PETRONAS, 31750 Tronoh, Perak, Malaysia 


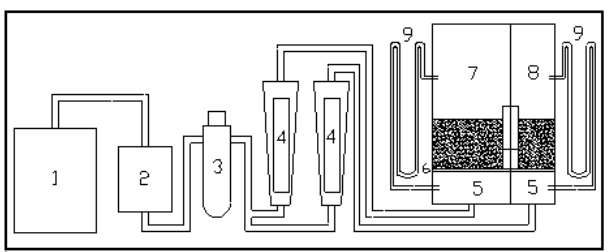

Fig. 1: Experimental setup (1) compressor; (2) dryer; (3) pressure regulator; (4) rotameter; 5: plenum;

(6) perforated distributor; (7) combustor; (8) gasifier; (9) manometer (Chok et al., 2009a)

This regime of constant $\mathrm{U}_{\mathrm{mf}}$ and $\mathrm{U}_{\mathrm{cf}}$ values can be observed in both compartments and can be established depending on the bed properties.

It is desirable to establish this regime for each compartment since the mixture characteristic velocities can be pre-determined using the bed material properties made up from entirely pure sand (inert) values. Within this regime, a single operational velocity can be set for the respective compartment based on the pure sand value and is independent from the variation of the palm shell size and weight percent in the mixtures (especially during combustion or gasification). Ultimately, the state of fluidization (e.g., bubbling or vigorously fluidized) and the condition of mixing/segregation in each compartment, that depend on the relative magnitude of the operational and characteristic velocities can be identified and maintained. Therefore, it is of great advantage to determine this regime for each compartment and the term "critical loading" is selected.

Meanwhile, various published $\mathrm{U}_{\mathrm{mf}}$ and $\mathrm{U}_{\mathrm{cf}}$ correlations are tested and compared with the experimental values.

\section{MATERIALS AND METHODS}

As the apparatus for this study is the same as described in (Chok et al., 2009a), only a brief description is included here. A schematic of the experimental setup is illustrated in Fig. 1. The cold flow model as shown in Fig. 2 has a 0.66 ID and is divided into 2 compartments i.e. combustor and gasifier by a vertical wall in 2:1 cross-sectional area ratio. The effective diameters, $\mathrm{D}_{\mathrm{e}}$ are computed as 25.7 and 41.3 $\mathrm{cm}$ for gasifier and combustor respectively (Chok et al., 2009a).

The experiments were carried out in both of the compartments at $0.4 \mathrm{~m}$ static bed height. Large amount of bed material is used, i.e., 77 and $101 \mathrm{~kg}$ respectively. 4 different types of sand and palm shell sizes are selected as the bed materials. The physical properties of the sand and palm shell are given in Table 1 .

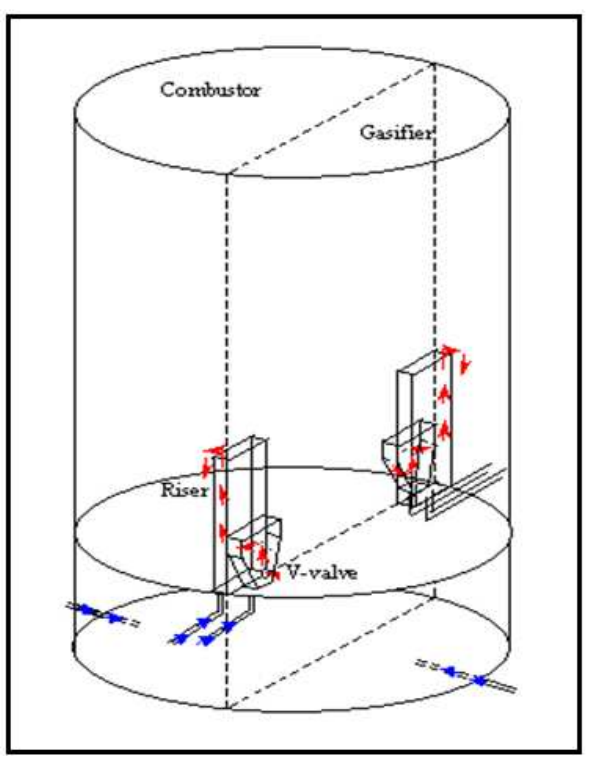

Fig. 2: Isometric view of CFBG (Chok et al., 2009a)

Table 1: Palm shell and sand properties

\begin{tabular}{lll}
\hline Properties & Palm shell & Sand \\
\hline Particle size/sieved range $(\mathrm{mm})$ & $1.77 /(+1.18-2.36)$ & 0.196 \\
& $3.56 /(+2.36-4.75)$ & 0.272 \\
& $7.13 /(+4.75-9.50)$ & 0.341 \\
& $11.75 /(+9.50-14.00)$ & 0.395 \\
Density $\left(\mathrm{kg} \mathrm{m}^{-3}\right)$ & 1,500 & 2.700 \\
Moisture $(\mathrm{wt} \%)$ & $8-10 \%$ & - \\
Weight percent $(\mathrm{wt} \%)$ & $2,5,10$ and15\% & - \\
\hline
\end{tabular}

\section{RESULTS}

Characteristic velocity profiles: Figure 3 shows the $\mathrm{U}_{\mathrm{mf}}$ and $\mathrm{U}_{\mathrm{cf}}$ profiles in the combustor at various palm shell sizes and weight percent with finest sand of $196 \mu \mathrm{m}$. For the smallest size palm shell of +1.18 $2.36 \mathrm{~mm}$, both the $\mathrm{U}_{\mathrm{mf}}$ and $\mathrm{U}_{\mathrm{cf}}$ values remain unchanged from the values of pure sand as in (Chok et al., 2009a). Similarly, for medium size palm shell of +2.36$4.75 \mathrm{~mm}$, these values remain constant except at 15 wt $\%$. With larger palm shell size of $+4.75-9.50 \mathrm{~mm}$, the characteristic value changes at $5-10 \mathrm{wt} \%$ but further increase of palm shell leads to severe channeling. This channeling condition is also observed for the largest palm shell size of $+9.50-14.00 \mathrm{~mm}$ where the characteristic velocities increase with the increase of palm shell wt $\%$ only up to $5 \mathrm{wt} \%$. Settlement of palm shell "chunks" are observed at higher weight percent for palm shell of $>4.75 \mathrm{~mm}$ even at the maximum capacity of air flow rate (10 times $\mathrm{U}_{\mathrm{mf}}$ of pure sand). Consequently, data that are not shown are due to poor fluidization. 
Am. J. Applied Sci., 7 (6): 773-779, 2010

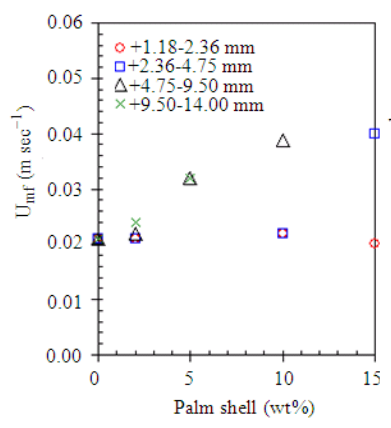

(a)

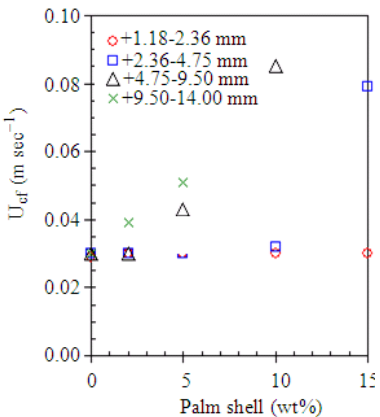

(a)
Fig. 3a and b: $U_{m f}$ and $U_{c f}$ in the combustor; sand of $196 \mu \mathrm{m}$ and palm shell of various sizes and weight percent

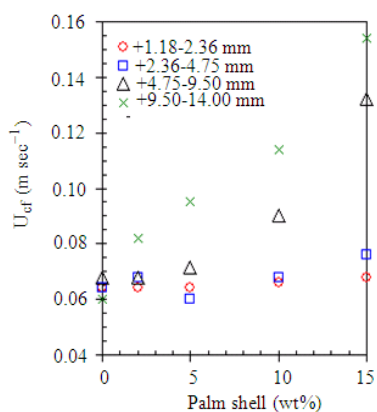

(a)

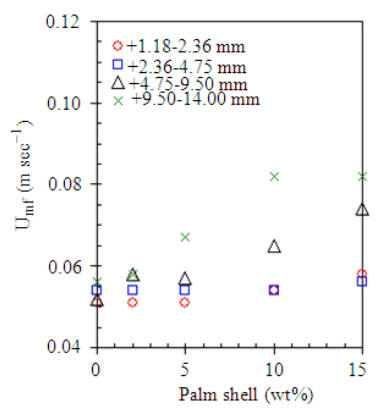

(b)
Fig. $4 a$ and b: $U_{m f}$ and $U_{c f}$ in the combustor; sand of $272 \mu \mathrm{m}$ and palm shell of various sizes and weight percent

Figure $4 \mathrm{a}$ and $5 \mathrm{a}$ indicate the $\mathrm{U}_{\mathrm{mf}}$ values for gasifier and combustor at various palm shell sizes and wt $\%$ with river sand of $273 \mu \mathrm{m}$.

The $\mathrm{U}_{\mathrm{mf}}$ values remain unchanged in the combustor for palm shell size $<4.75 \mathrm{~mm}$. Although similarly is found in the gasifier, the $U_{\mathrm{mf}}$ increases at palm shell of $+2.36-4.75 \mathrm{~mm}$ at $15 \mathrm{wt} \%$. The $\mathrm{U}_{\mathrm{mf}}$ increases at $\geq 10$ and $\geq 5 \mathrm{wt} \%$ for palm shell of $+4.75-9.50$ and +9.50 $14.00 \mathrm{~mm}$ respectively in the combustor. However, in the gasifier, the effect of palm shell of +4.75-9.50 and $+9.50-14.00 \mathrm{~mm}$ to the $\mathrm{U}_{\mathrm{mf}}$ is noticeable at $15 \mathrm{wt} \%$ and $\geq 5 \mathrm{wt} \%$ respectively.

The Fig. $4 b$ and $5 b$ indicate the $\mathrm{U}_{\mathrm{cf}}$ values for gasifier and combustor using the same river sand and palm shell composition. For palm shell size $<4.75$ $\mathrm{mm}$, the $\mathrm{U}_{\mathrm{cf}}$ values in both compartments remain nearly unchanged except palm shell of +2.36-4.75 mm at $15 \mathrm{wt} \%$ in the gasifier. For palm shell size of $+4.75-$ $9.50 \mathrm{~mm}, \mathrm{U}_{\mathrm{cf}}$ values for gasifier and combustor begin to show upward trends at $\geq 10 \mathrm{wt} \%$.

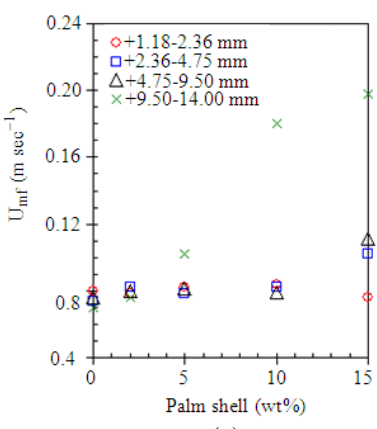

(a)

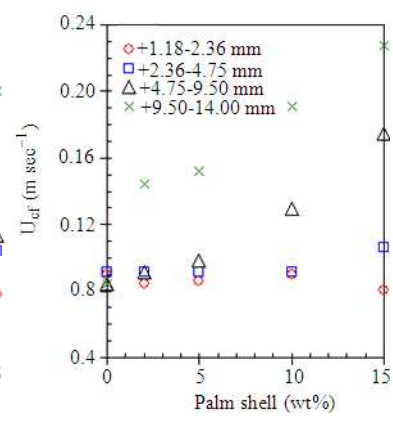

(b)
Fig. 5a and b: $U_{m f}$ and $U_{c f}$ in the gasifier; sand of 272 $\mu \mathrm{m}$ and palm shell of various sizes and weight percent

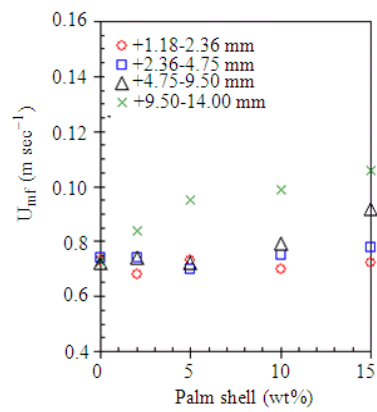

(a)

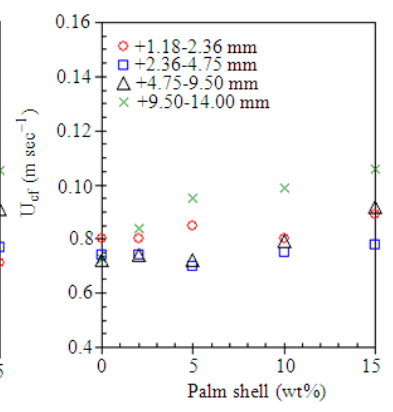

(b)
Fig. 6a and b: $U_{m f}$ and $U_{c f}$ in the combustor; sand of $341 \mu \mathrm{m}$ and palm shell of various sizes and weight percent

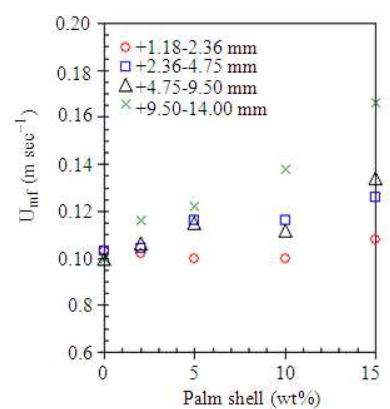

(a)

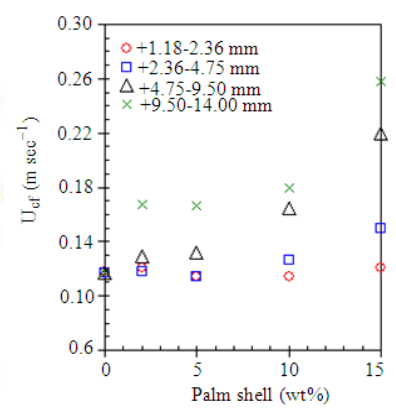

(b)
Fig. 7a and b: $U_{\mathrm{mf}}$ and $\mathrm{U}_{\mathrm{cf}}$ in the gasifier; sand of 341 $\mu \mathrm{m}$ and palm shell of various sizes and weight percent

Figure $6 \mathrm{a}$ and $7 \mathrm{a}$ indicate the $\mathrm{U}_{\mathrm{mf}}$ values for combustor and gasifier at various palm shell sizes and wt $\%$ with larger sand of $341 \mu \mathrm{m}$. No changes in the $U_{\mathrm{mf}}$ for palm shell size $<9.50 \mathrm{~mm}$ in the combustor, except for palm shell of $+4.75-9.50 \mathrm{~mm}$ at $15 \mathrm{wt} \%$. This trend 
is also similarly observed in the gasifier, but with significant $\mathrm{U}_{\mathrm{mf}}$ increase for palm shell of 2.36-4.75 and $+4.75-9.50 \mathrm{~mm}$ at $15 \mathrm{wt} \%$. In addition, for palm shell $>9.50 \mathrm{~mm}$, at $\geq 2 \mathrm{wt} \%$, increase of $U_{\mathrm{mf}}$ was observed in both compartments.

Figure $6 b$ and $7 b$ above indicate the $U_{c f}$ values for combustor and gasifier at various palm shell sizes and wt $\%$ with quartz sand of $341 \mu \mathrm{m}$. No changes in the $U_{\mathrm{cf}}$ for palm shell size $<4.75 \mathrm{~mm}$ in the combustor. Similar trend is also obtained in the gasifier except a noticeable $\mathrm{U}_{\mathrm{cf}}$ increase for palm shell of +2.36-4.75 $\mathrm{mm}$ at 15 wt $\%$. For palm shell of $+4.75-9.50 \mathrm{~mm}$ in the combustor, there is a marginal $\mathrm{U}_{\mathrm{cf}}$ increase at $15 \mathrm{wt} \%$. A steep increase in $\mathrm{U}_{\mathrm{cf}}$ is observed in the gasifier for palm shell of $+4.75-9.50 \mathrm{~mm}$ at $\geq 10 \mathrm{wt} \%$. For palm shell of $+9.50-14.00 \mathrm{~mm}$, incremental in $\mathrm{U}_{\mathrm{cf}}$ values are observed at $\geq 2 \mathrm{wt} \%$.

Figure 8 and 9 indicate the $\mathrm{U}_{\mathrm{mf}}$ and $\mathrm{U}_{\mathrm{cf}}$ values for combustor and gasifier at various palm shell sizes and wt $\%$ with quartz sand of $395 \mu \mathrm{m}$.

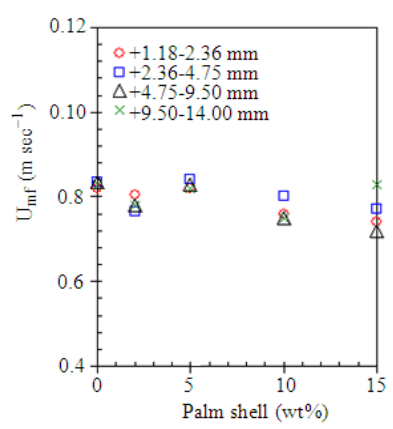

(a)

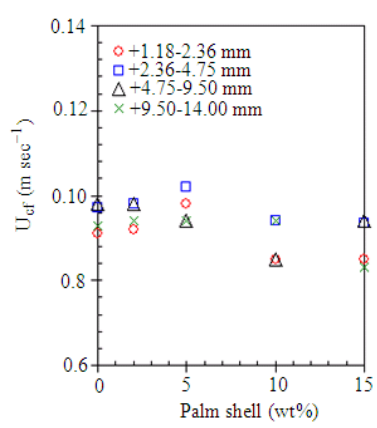

(b)
Fig. 8a and b: $U_{m f}$ and $U_{c f}$ in the combustor; sand of $395 \mu \mathrm{m}$ and palm shell of various sizes and weight percent

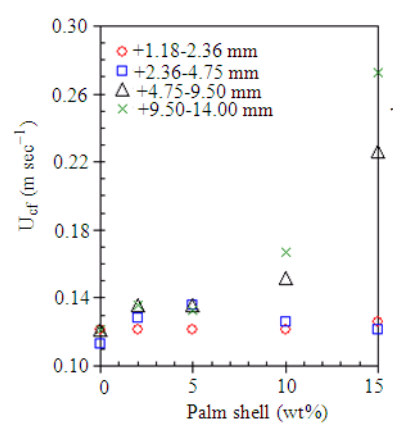

(a)



(b)
Fig. 9a and b: $U_{m f}$ and $U_{c f}$ in the gasifier; sand of 395 $\mu \mathrm{m}$ and palm shell of various sizes and weight percent
As shown in Fig. 8a, the $U_{m f}$ values in the combustor are relatively constant for all palm shell sizes at $\leq 5 \mathrm{wt} \%$. However, slight decrease in the $\mathrm{U}_{\mathrm{mf}}$ values are observed for palm shell sizes of $\leq 9.50 \mathrm{~mm}$ at $\geq 10 \mathrm{wt} \%$. For the largest palm shell size of $+9.50-14.00$ $\mathrm{mm}$, the $U_{\mathrm{mf}}$ values remain unchanged. Similarly, in Fig. $8 b$, the $U_{c f}$ values in the combustor remain nearly unchanged for all palm shell sizes at $\leq 5 \mathrm{wt} \%$. However, slight decrease in the $U_{c f}$ values at $10 \mathrm{wt} \%$ is noticeable for palm shell of $+1.18-2.36 \mathrm{~mm}$ and $+4.75-9.50 \mathrm{~mm}$. For the largest palm shell size of $+9.50-14.00 \mathrm{~mm}$, the $\mathrm{U}_{\mathrm{cf}}$ values remain unchanged up to $10 \mathrm{wt} \%$ and decreases at $15 \mathrm{wt} \%$.

In Fig. 9a, the $\mathrm{U}_{\mathrm{mf}}$ values for palm shell of $\leq 4.75 \mathrm{~mm}$ remains fairly constant up to $15 \mathrm{wt} \%$ in the gasifier. However, for palm shell size of $\geq 4.75 \mathrm{~mm}$, at $\geq 10$ wt $\%$, increase of $U_{\mathrm{mf}}$ values are observed. Similarly found in Fig. 9b, the $\mathrm{U}_{\mathrm{cf}}$ values for palm shell of $\leq 4.75 \mathrm{~mm}$ remains constant in the gasifier. For palm shell size $\geq 4.75 \mathrm{~mm}$, at $\geq 10 \mathrm{wt} \%$, increase of $U_{\mathrm{cf}}$ was observed.

Critical loading: Based on all the characteristic velocity profiles shown in Fig. 3-9, it is recognized that there are some instances where the mixtures $U_{m f}$ and $\mathrm{U}_{\mathrm{cf}}$ values remain nearly unchanged from its pure sand values. Therefore, it is of great advantage to determine this regime for each compartment and the term "critical loading" is selected. "Critical loading" is defined here as the maximum palm shell content (size and weight percent) that can be present in the sand where the mixtures $\mathrm{U}_{\mathrm{mf}}$ and $\mathrm{U}_{\mathrm{cf}}$ values remain absolutely of pure sand values. These values (of pure sand and mixture) are considered identical when the respective characteristic velocities variations between the bed materials are within $\pm 15 \%$. Table 2 and 3 show the critical loading for $\mathrm{U}_{\mathrm{mf}}$ and $\mathrm{U}_{\mathrm{cf}}$ in the combustor and gasifier respectively.

Table 2: Critical loading for $\mathrm{u}_{\mathrm{MF}}$ and $\mathrm{u}_{\mathrm{CF}}$ in the combustor

\begin{tabular}{|c|c|c|c|c|}
\hline \multirow{3}{*}{$\begin{array}{l}\text { Sand size } \\
(\mu \mathrm{m})\end{array}$} & \multicolumn{4}{|c|}{ Palm shell size $(\mathrm{mm})$} \\
\hline & $+1.18-2.36$ & $+2.36-4.75$ & $+4.75-9.50$ & $+9.50-14.00$ \\
\hline & \multicolumn{4}{|c|}{ Palm shell weight percent $(\mathrm{wt} \%) ; \mathrm{U}_{\mathrm{mf}} /\left(\mathrm{U}_{\mathrm{cf}}\right)$} \\
\hline 196 & $15 /(15)$ & $10 /(5)$ & $2 /(2)$ & $2 /(0)$ \\
\hline 272 & $15 /(15)$ & $15 /(10)$ & $5 /(5)$ & $2 /(0)$ \\
\hline 341 & $15 /(15)$ & $15 /(10)$ & $10 /(5)$ & $2 /(2)$ \\
\hline 395 & $15 /(15)$ & $15 /(15)$ & $15 /(15)$ & $15 /(10)$ \\
\hline \multicolumn{5}{|c|}{ Table 3: Critical loading for $\mathrm{u}_{\mathrm{MF}}$ and $\mathrm{u}_{\mathrm{CF}}$ in the gasifier } \\
\hline & \multicolumn{4}{|c|}{ Palm shell size $(\mathrm{mm})$} \\
\hline \multirow{2}{*}{$\begin{array}{l}\text { Sand size } \\
(\mu \mathrm{m})\end{array}$} & $+1.18-2.36$ & $+2.36-4.75$ & $+4.75-9.50$ & $+9.50-14.00$ \\
\hline & \multicolumn{4}{|c|}{ Palm shell weight percent ( $\mathrm{wt} \%) ; \mathrm{U}_{\mathrm{mf}} /\left(\mathrm{U}_{\mathrm{cf}}\right)$} \\
\hline 196 & - & - & - & - \\
\hline 272 & $15 /(15)$ & $10 /(10)$ & $10 /(5)$ & $2 /(0)$ \\
\hline 341 & $15 /(15)$ & $10 /(10)$ & $10 /(5)$ & $2 /(0)$ \\
\hline 395 & $15 /(15)$ & $15 /(15)$ & $10 /(10)$ & $5 /(5)$ \\
\hline
\end{tabular}


In both Table 2 and 3, it can be seen that for the smallest palm shell size of $+1.18-2.36 \mathrm{~mm}$, up to 15 wt $\%$ can be present in the mixture with any sand sizes without resulting significant changes in the mixture characteristic velocities from the pure sand values.

In addition, the critical loading increases with the increase of sand size but decreases with the increase of palm shell size. Meanwhile, the critical loading for the $\mathrm{U}_{\mathrm{mf}}$ is always equal or larger than the $\mathrm{U}_{\mathrm{cf}}$ value in both of the compartments. Overall, the largest sand size $(395 \mu \mathrm{m})$ has the highest critical loadings in both of the characteristic velocities.

Fig. 10 and 11 show the critical loading as a function of particle size ratio (palm shell/sand) in the combustor and gasifier respectively. The area below the lines and bounded by the horizontal axis represent the regime of the critical loading at various mixture size and composition. Generally, it can be observed that the critical loading decreases with the increase in particle size ratio i.e., in the trend of reducing. However, the formations of intermediate peaks occur in the combustor as shown in Fig. 10 for the mixture with sand of $395 \mu \mathrm{m}$. This is due to the increased in particles mixing as described earlier (Refer to Ratio of $U_{c f} / U_{m f}$ ) as observed in the larger compartment. In addition, the critical loading line for the $\mathrm{U}_{\mathrm{mf}}$ always lie on or above the values for the $\mathrm{U}_{\mathrm{cf}}$.



Fig. 10: Critical loading in the combustor

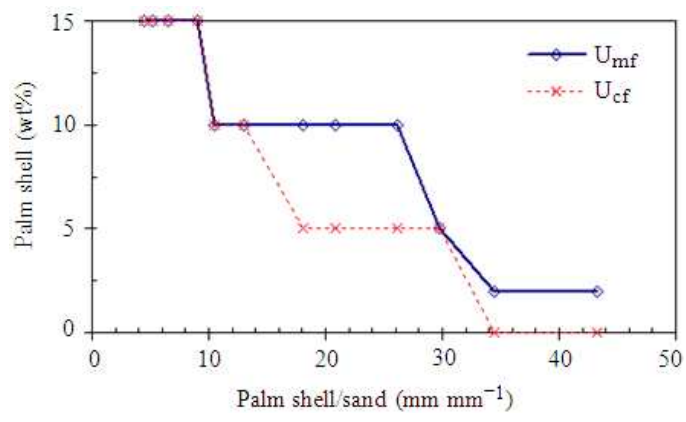

Fig. 11: Critical loading in the gasifier
$\mathbf{U}_{\mathrm{mf}}$ and $\mathbf{U}_{\mathrm{cf}}$ values comparison with correlations: The $\mathrm{U}_{\mathrm{mf}}$ and $\mathrm{U}_{\mathrm{cf}}$ values for sand/palm shell mixtures determined using the common methods for multicomponents system allow comparative studies to be carried out from the various published correlations.

Three different binary correlations namely Mourad et al. (1994); Goosens et al. (1971) and Thonglimp et al. (1984) are selected for comparison with experimental $U_{\mathrm{mf}}$ values. In addition, 4 different binary correlations namely Noda et al. (1986); Gauthier et al. (1999) and Rao et al. (2001) are selected for comparison with experimental $\mathrm{U}_{\mathrm{cf}}$ values. These researchers also utilized similar bed material properties and/or Geldart classification. The characteristic values for mixtures within the critical loading are not included since the mixtures $\mathrm{U}_{\mathrm{mf}}$ and $\mathrm{U}_{\mathrm{cf}}$ remain unchanged from the pure sand values.

In Fig. 12, it can be seen that all the $\mathrm{U}_{\mathrm{mf}}$ correlations generally are able to describe the qualitative variation in the sand-palm shell binary mixtures, i.e., the correlations are able to show the increasing or decreasing trends with respect to different sand-palm shell composition. However, as shown in Fig. 13, quantitatively, most correlations are unsatisfactory as they are either overestimate or under-estimate these values.

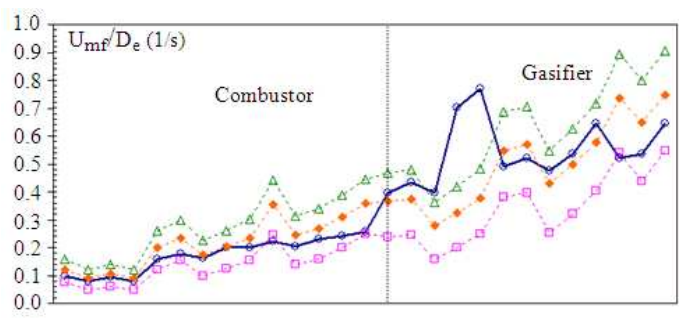

Fig. 12: Comparison of experimental (EXP) $\mathrm{U}_{\mathrm{mf}} / \mathrm{D}_{\mathrm{e}}$ with correlations; (o) (EXP); ( ) Mourad et al. (1994); (•) Goosens et al. (1971); ( $\Delta$ ) Thonglimp et al. (1984)

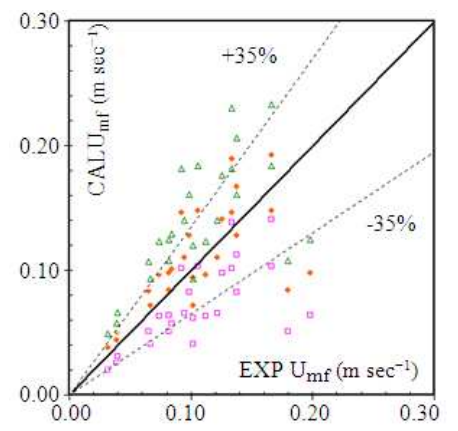

Fig. 13: Comparison of experimental (EXP) $\mathrm{U}_{\mathrm{mf}}$ with correlations; ( ) Mourad et al. (1994); (•) Goosens et al. (1971); ( $\Delta$ ) Thonglimp et al. (1984) 


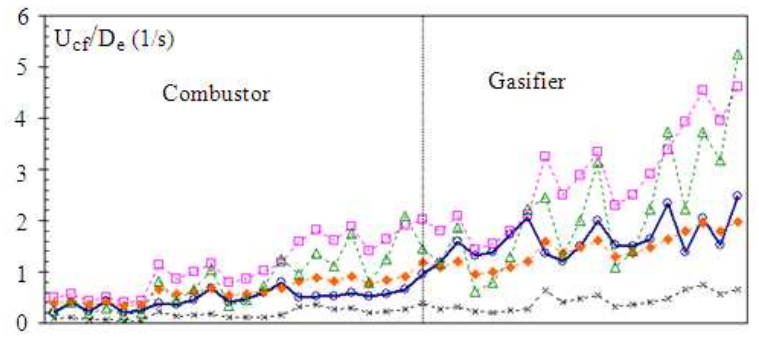

Fig. 14: Comparison of experimental (EXP) $U_{c f} / D_{e}$ with correlations; (॰) (EXP); ( ) Mourad et al. (1994); (*) Noda et al. (1986); (•) Gauthier et al. (1999); (₫) Rao et al. (2001)

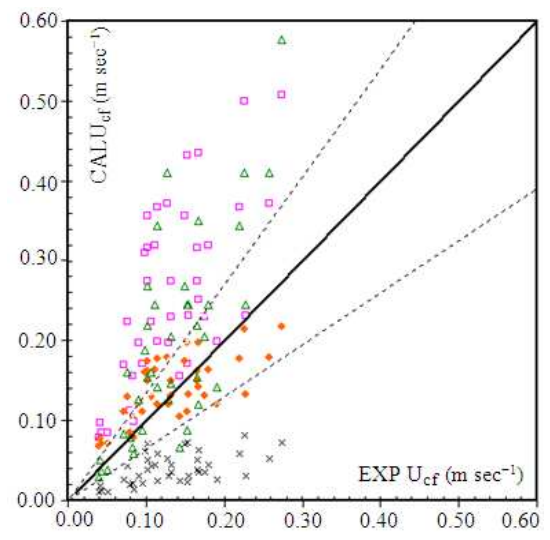

Fig. 15: Comparison of experimental (EXP) $\mathrm{U}_{\mathrm{cf}}$ with correlations; (口) Mourad et al. (1994); (*) Noda et al. (1986); (•) Gauthier et al. (1999);

( $\triangle$ ) Rao et al. (2001)

Similar found in Fig. 14 and 15, all the $U_{c f}$ correlations generally shows the qualitative $U_{c f}$ variation for the sand-palm shell binary mixtures but unable to give satisfactory prediction. The results from the various comparisons made on the existing $\mathrm{U}_{\mathrm{mf}}$ and $\mathrm{U}_{\mathrm{cf}}$ correlations at different palm shell and sand mixtures clearly show that significant deviation exceeding $\pm 35 \%$ from experimental values.

\section{DISCUSSION}

On one hand, using smaller sand particle reduces the superficial velocity necessary to establish fluidization when the palm shell components are smaller in sizes or weight percent in the mixtures. However, the tendency for segregation to occur is higher when the resulting particle size ratio (palm shell/sand) is higher due to the lower contribution of particle-particle collision (Chok et al., 2009b).
Consequently, higher superficial velocities are necessary to fluidize the bed mixtures especially if there is any formation of palm shell "chunks" that is enhanced by the present of larger palm shell size and weight percent.

To the contrary, when utilizing large sand particle in the mixture, although greater superficial velocity is required as compared to smaller sand size in order to establish fluidization when palm shell is smaller in sizes or weight percent, the tendency for segregation to occur reduces when the resulting particle size ratio is lower due to the greater contribution of particle-particle collision (Chok et al., 2009b). In addition, the critical loading increases allowing greater proportion of palm shell in all sizes to be present in the mixture without any significant increase of the mixture characteristic velocities from the pure sand value. This condition can be established in both compartments.

\section{CONCLUSION}

Taking into account all of the $\mathrm{U}_{\mathrm{mf}}$ and $\mathrm{U}_{\mathrm{cf}}$ values at different palm shell and sand mixtures and fitting all these curves to a single mathematical equation is seemingly impractical. Although for a specific palm shell size and sand, $\mathrm{U}_{\mathrm{mf}}$ and $\mathrm{U}_{\mathrm{cf}}$ can be fitted into an equation but no correct equation and model which can correlate all of the data that have been found thus far. Direct utilizing of the experimental values for the operation of sand-palm shell in fluidized bed is essential. Alternatively, identifying the critical loading for this mixture provides a convenient yet robust system where its operational velocity can be pre-determined using bed material properties made up from entirely pure sand (inert) values.

\section{REFERENCES}

Chok, V.S., S.K. Wee, A. Gorin and H.B. Chua, 2009a. Effect of particle and bed diameter on characteristic velocities in Compartmented Fluidized Bed Gasifier. Proceeding of the 2nd CUTSE International Conference: Progress in Science and Engineering for Sustainable Development, Nov. 24-25, Curtin University of Technology, Sarawak, Malaysia, pp: 1-5.

Chok, V.S., A. Gorin and H.B. Chua, 2009b. Minimum and complete fluidization velocity for sand/palm shell binary mixtures, Part I: Fluidization behavior and characteristic velocities. Proceeding of the 2nd CUTSE International Conference: Progress in Science and Engineering for Sustainable Development, Nov. 24-25, Curtin University of Technology, Sarawak, Malaysia, pp: 1-5. 
Chok, V.S., L.F.B. Chin, S.K. Wee, W.W. Tang and A. Gorin, 2007. Hydrodynamics studies of sand/palm shells binary mixtures in Compartmented Fluidized Bed Gasifier (CFBG). Proceeding of the 1st Engineering Conference on Energy and Environment, Dec. 2007, UNIMAS, Kuching, Sarawak, pp: 301-306.

Fauziah, M., A.R. Nornizar, A. Nornizar, A. Azil Bahari and M.J. Tajuddin, 2008. Cold flow binary fluidization of oil palm residues mixture in a gassolid fluidized bed system. Pertanika J. Sci. Technol., 16: 201-212.

Gauthier, D., S. Zerguerras and G. Flamant, 1999. Influence of the particle size distribution of powders on the velocities of minimum and complete fluidization. Chem. Eng. J., 74: 181-196, DOI: 10.1016/S1385-8947(99)00075-3

Goosens, W.A.R., G.L. Dumont and G.J. Spaepen, 1971. Fluidization of binary mixtures in the laminar flow reaction. AlChE Symp. Ser., 67: 38-45.
Mourad, M., M. Hemati and C. Laguerie, 1994. Hydrodynamics of fluidized bed dryer: Determination of characteristics of fluidization velocities of mixtures of corn and sand, Powder Technol., 80: 45-54, DOI: 10.1016/00325910(94)87004-7

Noda, K., S. Uchida, T. Makino and H. Kamo, 1986. Minimum fluidization velocity of binary mixtures of particles with large size ratio. Powder Technol., 46: 149-154. DOI: 10.1016/0032-5910(86)80021-3

Rao, R., T. Ram and J.V. Bheemarasetti, 2001. Minimum fluidization velocity of mixtures of biomass and sands. Energy, 26: 633-644. DOI: 10.1016/S0360-5442(01)00014-7

Thonglimp, V., N. Hiquily and C. Laguerie, 1984. Minimum fluidization velocity and expansion of layers of mixtures of particulates solids fluidized by a gas. Powder Technol., 39: 223-239. DOI: 10.1016/0032-5910(84)85040-8 